\title{
A Pesquisa Histórica no Cinema Latino- americano: Perspectivas e desafios na era digital
}

\author{
Andrea Cuarterolo \\ Universidad de Buenos Aires/Consejo Nacional de Investigaciones \\ Científicas y Técnicas (CONICET), Argentina \\ acuarterolo@gmail.com \\ https://orcid.org/oooo-0003-3724-1492
}

\section{Eduardo Morettin}

Universidade de São Paulo/CNPq, Brasil

eduardomorettin@usp.br

https://orcid.org/o000-0002-1207-4969

\section{Georgina Torello}

\author{
Universidad de la República, Uruguai \\ georgina.torello@gmail.com \\ https://orcid.org/oooo-0002-6491-769X
}

RESUMO O objetivo principal do dossiê é o de refletir sobre os rumos atuais da pesquisa histórica em cinema no mundo latino-americano, pensando os desafios impostos pela contemporaneidade e as perspectivas existentes. Os esforços no sentido de elaborar um sistema de compreensão das experiências ocorridas no passado que relacione a análise fílmica e os dados da produção cinematográfica em suas diferentes manifestações às questões de contexto constituem uma das tarefas do trabalho do historiador. A nossa intenção é de avaliar o estatuto de novas abordagens, novos objetos e novos problemas nas pesquisas históricas mais recentes e os possíveis caminhos a serem enfrentados na articulação entre teoria e prática. Como se sabe, a pesquisa em história do cinema sempre dependeu dos arquivos audiovisuais e Cinematecas, muitos deles em risco na América Latina, como é o caso da Cinemateca Brasileira. Sempre é preciso ressaltar a importância estratégia dos acervos, pois armazenam filmes, cartazes, roteiros, reportagens - documentos que, articulados pelo pesquisador ao método escolhido, à formação de núcleos temáticos e de conceitos, e à constituição de uma periodização, constroem a história de determinada cinematografia. Em 2020 a forma privilegiada de acesso às fontes foi por meio do digital, o que certamente acentuou os desafios que já se colocavam desde o início do século XXI. Se, com os filmes, a dimensão de apreensão de sua visualidade está se modificando com o seu visionamento em celulares e computadores, há uma crescente 
perda de contato com a materialidade das fontes pelo uso contínuo de bases de dados e repositórios digitais. Pensar as implicações desta situação para a pesquisa histórica em cinema constitui um dos objetivos do presente dossiê.

PALAVRAS-CHAVE Historiografia do cinema; pesquisa histórica; história do cinema.

Desde o início do novo século, a pesquisa histórica do cinema latinoamericano experimentou um processo de consolidação e profissionalização. Sem dúvida, foram fatores fundamentais para explicar este fenômeno o crescente desenvolvimento dos estudos de cinema em nível universitário, o surgimento e o fortalecimento de associações científicas, ${ }^{1}$ o apoio, mesmo que diminuto se comparado com outras áreas, ao campo conferido pelas diversas agências de fomento por meio de bolsas ou financiamentos a projetos de pesquisa, e a efervescência e dinamismo da produção fúlmica latino-americana contemporânea. Porém, como aponta Paulo Paranaguá, a pesquisa sobre a história do cinema na América Latina dependeu historicamente tanto da academia quanto do arquivo, duas instituições tradicionalmente em tensão e com "missões e prioridades diferentes, por vezes conflitivas" $(2015,24) .^{2}$ Por décadas, a precariedade e fragilidade dos acervos e das cinematecas latino-americanas, e a consequente dificuldade ou impossibilidade de acesso às fontes que estas armazenavam, marcaram várias gerações de historiadores, que encontraram nestes obstáculos uma barreira até para os que se dispunham a escrever sua história em perspectiva positivista, pautada pela reconstituição cronológica de eventos associados a nomes, filmes e temas, impedimento que teve impacto também nas abordagens históricas de caráter nacionalista, viés presente nos primeiros trabalhos. Se no século passado era difícil acessar ao patrimônio cinematográfico do próprio país, a possibilidade de visionar filmes e documentos de outras regiões da América Latina se tornava uma tarefa quase utópica, que obstruiu por anos qualquer aproximação de caráter

\footnotetext{
${ }^{1}$ Exemplos neste sentido são a Sociedade Brasileira de Estudos de Cinema e Audiovisual (SOCINE), criada no Brasil em 1996, o Seminario Permanente de Análisis Cinematográfico (SEPANCINE), que iniciou suas atividades em 2005, no México, a Asociación Argentina de Estudios sobre Cine y audiovisual (AsAECA), fundada em 2008, e o uruguaio Grupo de Estudios Audiovisuales (GEstA), de 2009. Podemos mencionar também a seção Film Studies da Latin American Studies Association (LASA) e o Latino Caucus Group da Society for Cinema and Media Studies (SCMS).

${ }^{2}$ No caso brasileiro, em particular no que diz respeito ao estado de São Paulo, os vínculos entre a Cinemateca Brasileira (CB) e a Universidade de São Paulo (USP) sempre foram estreitos. Paulo Emilio Salles Gomes foi o responsável, em 1946, pela criação da CB e, ao mesmo tempo, em meados dos anos 1960, do curso de cinema na USP.
} 
comparativo. Neste sentido, a consolidação da investigação histórica do cinema no século XXI está profundamente relacionada com o crescimento e a diversificação dos repositórios fílmicos regionais e com a profunda transformação nas práticas de arquivo, produto de uma tardia, porém acelerada, "virada digital".

\section{A pesquisa histórica em cinema e a "virada digital"}

Com efeito, à criação de novos arquivos, muitos deles cada vez mais especializados temporal, geográfica ou tematicamente, se somou um processo gradual de digitalização de acervos e coleções, que possibilitou o aumento exponencial de fontes fílmicas e extra-fílmicas disponíveis. Desde os primeiros anos deste século, em diversos países tivemos ações de resgate e, principalmente, de difusão de filmes latinoamericanos - em especial os do período silencioso ${ }^{3}-$, que conseguiram expressivo alcance por meio da criação de repositórios digitais de acesso aberto e gratuito, que foram bem sucedidos em dar a estes materiais uma visibilidade até então inimaginável. Junto ao maior acesso aos filmes, tivemos no mesmo período uma crescente disponibilidade on-line de fontes primárias extra-fílmicas. Potencializadas pelo rápido desenvolvimento da tecnologia computacional, diversas instituições colocaram à disposição para consulta desde fotografias e cartazes até coleções completas de revistas de cinema e outros materiais de caráter hemerográfico. ${ }^{4}$ Tendo em vista a elevada porcentagem de filmes perdidos da cinematografia latino-americana, especialmente os produzidos no período silencioso e clássico, o acesso virtual a este tipo de documento é crucial hoje para que sejam preenchidas as lacunas impostas pela inexistência destas obras, como mostram vários dos artigos presentes neste dossiê.

Esta "virada digital" significou para a historiografia do cinema latinoamericano um verdadeiro ponto de inflexão, potente catalizador para a pesquisa que foi acompanhada por novas abordagens sobre a história do cinema. Como sugere Lila Caimari (2017), a democratização da informação promovida por este recente fenômeno em poucos anos deslocou a figura do "pesquisador detetive", capaz de encontrar

\footnotetext{
${ }^{3}$ Para maiores informações sobre este fenômeno e seu impacto nos estudos do primeiro cinema latinoamericano ver Cuarterolo (2017).

${ }^{4}$ Sobre o desenvolvimento da digitalização de materiais hemerográficos relativos ao cinema ver Gionco (2020).
}

aniki A Pesquisa Histórica no Cinema Latino-americano | Historical Research in Latin-american Cinema 
materiais ocultos ou inacessíveis, para a do "pesquisador sobrecarregado", em virtude de ter diante de si uma documentação cada vez mais vasta. Este novo momento tem impactado de forma inquestionável o desenho e a escala das pesquisas históricas na região, que passaram de abordagens de caráter panorâmico e focados em determinados centros produtores a temas cada vez mais específicos e descentralizados.

No entanto, no âmbito latino-americano, esta "virada digital" ocorreu dentro da estrutura de instituições arquivísticas que carregam deficiências de longa data, dando lugar a um período de transição em que "abundância e escassez documental (e a memória muito persistente de escassez) coexistem e se aprimoram em uma nova configuração" (Caimari 2017, 74). A isto podemos acrescentar que a estabilidade e permanência destes arquivos digitais na América Latina é incerta, pois depende em grande medida de fatores políticos e econômicos que ameaçam constantemente sua continuidade e funcionamento. Dois tristes exemplos desta situação de precária fragilidade podem ser fornecidos, por um lado, pelo desaparecimento, na Argentina, do Catálogo Acceder, uma rede de conteúdos digitais na qual convergiam diversas bases de dados das instituições de Buenos Aires e que permitia, por meio de instrumento de busca on-line, localizar digitalizações de filmes, fotografias, cartazes, documentos, vestuário e fonogramas, entre outras fontes de interesse que se encontravam armazenadas nestes repositórios. ${ }^{5}$ Recentemente, teve destino parecido o precioso Banco de Conteúdos Culturais (BCC) da Cinemateca Brasileira, que, devido ao abandono estatal e à falta de técnicos qualificados em sua sede principal, ficou fora do ar por mais de um ano em plena pandemia, impossibilitando a continuidade de pesquisa daqueles que dependiam deste acesso remoto para dar seguimento às suas investigações. ${ }^{6}$

\footnotetext{
${ }^{5}$ Em meados de 2015, esta plataforma foi abrupta e inexplicavelmente fechada, impedindo o acesso a centenas de documentos e registros e encerrando de forma inesperada anos de trabalho consumidos em seu desenvolvimento.

${ }^{6}$ Felizmente, o BCC voltou ao ar em novembro de 2021, no mesmo dia em que a Sociedade de Amigos da Cinemateca assumiu, por meio de contrato emergencial com duração de três meses, a gestão da CB. Infelizmente, seu acervo documental não teve melhor sorte durante o período de abandono. Um incêndio nos depósitos na sede Vila Leopoldina da Cinemateca, em 29 de julho passado, destruiu, dentre outros materiais, cerca de quatro toneladas de documentação impressa referente às políticas cinematográficas desenvolvidas pelo Estados desde os anos 1960. Sobre o assunto ver Morettin (2021). Este fato coloca novamente em evidência a fragilidade que marca a trajetória dos arquivos fílmicos da região, como mencionamos, incluindo aqueles que foram considerados, em outros tempos, instituições modelares.
} 
Da mesma forma, a situação criada pela disponibilização on-line de documentos fílmicos e extra-fílmicos nos obrigou a repensar os nossos conceitos tradicionais de arquivo e a adotar novas metodologias, além de nos cercarmos de cuidados adicionais diante de nossas investigações. Em primeiro lugar, toda digitalização implica uma seleção que adota critérios nem sempre claros, além de um inevitável componente subjetivo. Rick Prelinger (2007) cunhou o termo "archival privilege" para se referir às prerrogativas que possuem os que conservam o patrimônio audiovisual para divulgar os documentos que custodiam, deixando de lado um importante volume de documentos potencialmente úteis, que permanecem desconhecidos para os pesquisadores. Este é um fenômeno que se agrava no caso da América Latina, se levarmos em conta que a ausência de catálogos e instrumentos de pesquisa abertos à consulta pública é um problema histórico. Em segundo lugar, como sugere Rielle Navitski (2014), se a utilização cada vez mais frequente de ferramentas de busca como o OCR nos possibilita acelerar de forma muito rápida a pesquisa, também faz com que se perca o contexto, limitando nossa procura somente aos documentos que respondem aos parâmetros escolhidos. Em terceiro lugar, os filmes digitalizados, uma vez que começaram a se multiplicar na web, não raro se desvinculam de seu lugar de procedência, sem informações claras sobre a origem e características da cópia e/ou versão acessadas. ${ }^{7}$ Este também é um fator que ganha outra dimensão na América Latina, uma vez que os filmes digitalizados tendem a circular com mais frequência do que em outras regiões por canais informais fora da esfera institucional e de suas bases de dados. Por último, esta "virada digital" provocou uma progressiva perda de contato com os documentos originais, fenômeno que é universal mas que foi agravado em nosso contexto em virtude das precárias e problemáticas condições de preservação, restauração, visualização e manipulação do patrimônio audiovisual, sendo a obsolescência técnica uma ameaça constante. Este crescente desapego em relação às fontes originais impactou as práticas de arquivo, mas também as próprias pesquisas, tornando mais difícil que uma série de temas e abordagens associados à materialidade desses documentos possa ser explorada. ${ }^{8}$

\footnotetext{
${ }^{7}$ Eduardo Morettin (2014) trouxe vários exemplos a respeito deste tipo de problema.

${ }^{8}$ Os poucos trabalhos que recuperam este enfoque são justamente os de pesquisadores que trabalham nos próprios arquivos, responsáveis pela custódia dos documentos, conferindo sentido ao "archival privilege" de que fala Rick Prelinger (2007).
} 


\section{A problemática histórica em tempos virtuais: percursos e potencialidades}

As questões acima pontuadas destacam um dos movimentos ligados ao fazer história do cinema, tendo em vista a forma como os acervos são constituídos e as escolhas do que restaurar e/ou colocar à disposição on-line. Devemos evitar a crença de que tudo se resume ao contato com estas fontes, em acervo físico ou on-line, e à busca de dados antes nunca pesquisados. O "novo" ou a "novidade" aqui devem ser entendidos não apenas pela descoberta de alguma informação ainda não explorada ou pelo tratamento de temáticas antes não abarcadas, pois é possível realizar a respeito deles história a mais tradicional possível. Cabe, em qualquer trabalho feito nesta perspectiva, explicitar a "problemática histórica" que orienta a pesquisa em sua relação com o recorte proposto, seu objeto e suas fontes. Como diz Ulpiano Bezerra de Meneses (2003, 28), a preocupação deve residir em formular "problemas históricos, para serem encaminhados e resolvidos por intermédio de fontes visuais, associadas a quaisquer outras fontes pertinentes". Se as perguntas não são formuladas, não existem problemas a serem resolvidos, nem método a ser proposto. ${ }^{9}$

Um dos efeitos inversos da ampliação do acesso virtual à documentação pode ser constatado no fato de que hoje não são raras as pesquisas que se contentam com a enumeração de fatos, apresentados em ordem cronológica e ancorados em uma sucessão de documentos que se sobrepõem, como se isso contemplasse o fazer história. Talvez pior, esse acúmulo de informações revela a crença de que os documentos são os objetos de pesquisa. Como pontua Meneses, "não são pois documentos os objetos da pesquisa, mas instrumentos dela: o objeto é sempre a sociedade" (2003, 28).

Trata-se, portanto, de avaliar no exame das fontes o reconhecimento da "cidadania plena" do cinema nos estudos históricos, reconhecimento que passa, portanto, pela sua valorização estética e por sua articulação com outros domínios das ciências humanas, resgatando-o do oceano repleto de um sem número de datas e nomes, em obras que parecem depositar sua crença na disposição cronológica para conferir sentido ao que se chama de história. Retomando o livro paradigmático lançado por Pierre Nora e Jacques Le Goff (1976a, 1976b, 1976c, na versão

\footnotetext{
${ }^{9}$ Vicente Sánchez-Biosca $(2017,400)$ afirma: "uma das tarefas mais difíceis do intelecto consiste precisamente em saber formular as perguntas".
} 
brasileira), a pergunta a ser feita em relação aos objetos e problemas de pesquisa diz respeito à contribuição dada ao campo no que concerne à inserção do cinema no campo de estudos históricos. ${ }^{10}$ Devemos, portanto, seguindo ainda o historiador Ulpiano Bezerra de Meneses, estar atentos ao que é estudado em "áreas vizinhas", evitando "o entendimento superficial e teoricamente insuficiente da natureza do [áudio]visual e, por consequência, do iconográfico, e assim por diante" $(2003,20){ }^{11}$

Dentre os desafios que os pesquisadores enfrentam ao escrever a história do cinema no século XXI, formulação próxima ao título de um artigo recente de Sheila Schvarzman (2017), há certamente o de contemplar as histórias singulares diante do que a autora chama de "centros hegemônicos", mas acreditamos que uma das tarefas que se impõem reside na avaliação da dimensão estética, expressa em nosso campo pelo lugar da análise fílmica. Dentre os trabalhos que poderiam ser recuperados aqui, a ampliação das balizas teóricas e metodológicas trazidas por historiadores como Sylvie Lindeperg (2007) deve ser mencionada. Seu exame amplo e rigoroso do que se encontra na gênese e na circulação de Noite e Neblina (Nuit et Brouillard, 1955), de Alain Resnais, sem deixar de lado as questões estéticas, corrobora o entendimento de que a análise fílmica é fundamental, mas que sozinha não consegue dar conta da dimensão histórica presente no cinema. Nessa relação dialética entre obra e contexto, Lindeperg está atenta ao que escapa do controle, pois a filmagem, mesmo em um projeto tão preparado como o de Resnais, pode trazer novos elementos/sentidos à obra $(2007,94)$.

Com estas perspectivas, todos os artigos deste dossiê se caracterizam pelo trabalho inovador com o arquivo tanto por recuperar acervos quase desconhecidos quanto por propor abordagens e caminhos originais sobre temas e documentação já estudados. Seus autores também colocam em evidência os benefícios e os desafios trazidos por essas novas práticas de arquivamento, propondo metodologias específicas para enfrentar seus temas e objetos de pesquisa em contexto de constante transformação.

\footnotetext{
${ }^{10}$ Como se sabe, os títulos da versão brasileira de Faire l'Histoire (a rigor, fazer história, no sentido de produzi-la) fazem menção à corrente historiográfica a qual os textos reunidos se vinculam, a chamada Nouvelle Histoire, ou seja, Nova História. Associar o adjetivo 'novo' a problemas, objetos e abordagens não deixa de ser esperta iniciativa editorial, lançando interesse do leitor incauto a algo que no original se apresentava de outra forma.

${ }^{11}$ Meneses está preocupado com as fontes visuais. O ‘áudio’ é acréscimo nosso.
} 


\section{Repensar historicamente o cinema latino-americano: novas temáticas, novas metodologias}

A renovação da academia latino-americana em matéria de estudos cinematográficos é o resultado, nas últimas décadas, não apenas da transformação e desenvolvimento de seus arquivos, tanto analógicos como digitais, de seus laboratórios de preservação cada vez mais profissionalizados, ou de sua potente revisão historiográfica e de seus novos modos de pensar e entender práticas e processos, mas também da notável inovação nas formas de conceber e definir o próprio objeto e, portanto, de identificar temas, abordagens e metodologias novos. ${ }^{12}$ Marca evidente desta renovação temática - para além dos estudos individuais, divulgados em revistas, livros e teses de doutoramento que, por razões de espaço, não mencionamos aqui - é a efervescência de publicações coletivas que, nos últimos anos, pensam de diferentes lugares o campo audiovisual latino-americano. Uma mirada que, depois de se ter focado quase que exclusiva e sistematicamente na reconstrução histórica do nacional, ${ }^{13}$ expande-se para construir mapas regionais, atender aos cruzamentos intermediais, ${ }^{14}$ procurar as conexões transnacionais, ${ }^{15}$ e reconsiderar as questões de gênero. ${ }^{16}$

Os seis artigos selecionados para o dossiê que organizamos refletem a poliédrica inovação temática presente nos estudos acadêmicos latino-

\footnotetext{
${ }^{12}$ Entre os trabalhos que propõem novas possibilidades de abordagem ao objeto, ver o dossiê coordenado por Nicolás Poppe (2018) para Vivomatografías. Sobre os outros usos do material de arquivo, como o seu reemprego em produções contemporâneas, ver o dossiê coordenado por Beatriz Tadeo Fuica e Sarah Barrow (2015) para New Cinemas, e o dossiê coordenado por Ángel Miquel e David M. J. Wood (2016), também para Vivomatografías.

${ }^{13}$ Cabe destacar que, como sugere o recente trabalho de Zavala Alvarado (2017) acerca do estado da arte sobre os estudos deste campo na América Latina, a categoria 'nação' continua sendo central nos estudos desenvolvidos em diferentes países.

${ }^{14}$ Sobre a arte e suas relações intermediais, entre outros, com o cinema, ver o dossiê organizado por María Fernanda Pinta e Jorge Sala (2020) para Caiana. Revista de Historia del Arte y Cultura Visual del Centro Argentino de Investigadores de Arte (CAIA).

${ }^{15}$ Neste sentido, são dignas de nota, entre os esforços para superar o paradigma nacional, a antologia coordenada por Javier Cossalter (2021), cuja estrutura sugere lucidamente - ainda que o título do projeto não o indique - um duplo olhar: nacional e transnacional, e o estudo sobre cinema argentino e mexicano do período clássico, editado por Ana Laura Lusnich, Alicia Aisemberg e Andrea Cuarterolo (2017). Os laços e apropriações internacionais do cinema da região têm sido pensados por Rielle Navitski e Nicolas Poppe (2017), em dossiês coordenados por Georgina Torello e Cecilia Lacruz (2020) para a Revista Encuentros Latinoamericanos, e por Georgina Torello (2020) para Vivomatografías, e, por fim, no volume coordenado por Laura Miranda e Lucía Rodríguez Riva (2019).

${ }^{16}$ Entre os estudos que poderíamos citar, há as pesquisas sobre gêneros e afetos, como o livro compilado por Irene Depetris Chauvin e Natalia Taccetta (2019), e o dossiê "Feminismos" (2021), publicado em En la Otra Isla. Revista de Audiovisual Latinoamericano, disponível em: http://enlaotraisla.com/index.php/Laotraisla/issue/view/4. Dentre os que surgirão em breve, lembremos o dossiê "Documents for a feminist history of Latin American cinema", que está presentemente a ser editado por Marina Cavalcanti Tedesco, Elizabeth Ramírez-Soto e Isabel Seguí para a revista Studies in Spanish and Latin American Cinemas.
}

aniki A Pesquisa Histórica no Cinema Latino-americano | Historical Research in Latin-american Cinema 
americanos, traçando uma cartografia que compreende México, Brasil, Argentina, Chile e Uruguai. Uma reflexão teórica alentada sobre a ausência física e simbólica das imagens - sobre a perda, a destruição e o esquecimento - serve como moldura, em "Archivo, Memoria y Resignificación: Acercamientos al cine de reapropriación en México", de J. Pablo Romo Álvarez e Elissa J. Rashkin, para analisar a prática de reutilização de materiais de arquivo pertencentes a outras pessoas e suas implicações (entre outras, o novo sentido atribuído aos materiais utilizados, a neutralização de significados por parte do mercado ou, em contramão, o seu reemprego de forma crítica). O artigo se encerra com a análise dos curta-metragens ¡Allá Vienen!, de Ezequiel Reyes, e Fantasmas del adiós, de Ximena Cuevas, duas produções que recorrem a arquivos familiares, exibidas no festival ULTRAcinema, em 2018 e 2019. Se o artigo de Romo Álvarez e Rashkin apresenta uma validade transversal, que abrange, potencialmente, toda a história do cinema e de suas perdas, os demais textos se concentram em novos estudos de caso, recuperando lacunas específicas, repondo cuidadosamente fragmentos, olhando para objetos ou relações raramente examinadas e, de certo, reintegrando vozes, imagens e processos por meio de sua análise. Em seu artigo "Reflexões sobre o Acompanhamento Musical do Primeiro Cinema: O caso do carioca Cinema Chantecler (1911)", Danielle Crepaldi Carvalho se debruça sobre as interconexões há muito negligenciadas - em boa parte devido à escassez de fontes, à dificuldade de acesso às que existem e à sua perda - entre o cinema silencioso e a música. Combinando a pesquisa em arquivos físicos e digitais, a autora se ocupa dos programas musicais que acompanharam as sessões cinematográficas de uma sala específica. Trata-se de um material raro - neste caso não tanto pelas potenciais perdas, mas pela peculiaridade, como prática, de publicar à época programas musicais pormenorizados. A descoberta deste corpus é retomada pela autora para discutir a bibliografia internacional sobre o tema em diálogo com o caso específico brasileiro. Neste sentido, um dos aportes mais significativos do trabalho é o acompanhamento metódico do "esforço" do Cinema Chantecler para estabelecer um diálogo entre os gêneros cinematográficos e musicais, atribuindo aos filmes, conforme o caso, formas musicais classificadas como "alta" ou "baixa". Ou seja, se o material não revela, como em outras áreas, indícios da composição de acompanhamentos originais, ele estabelece uma forte apropriação do repertório musical e mesmo dos termos em que essa apropriação ocorreu. 
Sobre um caso particular de relações transnacionais se concentra "La Circulación Internacional del Cine Argentino en el Período Clásico: El caso de la Southern California Film Society (1939)”, de Alejandro Kelly Hopfenblatt e Iván Morales. Investigando (e resgatando, aliás, para a memória) documentos institucionais e hemerográficos anteriormente negligenciados, e chamando nossa atenção para a necessidade metodológica, cada vez mais evidente, de uma pesquisa que cruze arquivos nacionais e internacionais, os autores concentram sua atenção sobre o papel dos agentes norte-americanos na produção e distribuição do cinema clássico argentino no exterior. Pedra de toque do artigo é a exibição, no mercado norte-americano, de dois filmes argentinos na Southern California Film Society, Puerta cerrada (Luis Saslavsky, 1939) e Alas de mi patria (Carlos Borcosque, 1939). Trata-se de uma empresa que, interessada em cobrir a história do cinema até aquele momento, exibindo pré-estreias e divulgando, entre seus membros, produções da Europa e da América do Sul que não chegavam aos circuitos comerciais, estabeleceu acordos com instituições norte-americanas (museus e universidades) e do resto do mundo. Como assinalam os autores, também informou os produtores locais sobre o mercado internacional. Valendo-se de bibliografia recente, o artigo se preocupa com a distribuição, ou seja, com o caráter estritamente comercial do cinema que, como apontam, tradicionalmente não se encontra na agenda dos estudos cinematográficos.

A pesquisa de Livia Perez sobre a produtora Cinematográfica Terras do Brasil (CTB), fundada por Tânia Simões e Jovita de Almeida, coloca em primeiro plano a participação de mulheres na sempre incipiente indústria cinematográfica brasileira dos anos 1950. Em contexto de aumento da produção de filmes, como era o caso do estado de São Paulo ao final dos anos 1940 e inícios da década seguinte, com a criação de várias produtoras, a CTB aparece como a única empresa dirigida por mulheres no período. "Estrada da Vida (1952) e a Cinematográfica Terras do Brasil: A presença das mulheres no cinema brasileiro do início dos anos 1950" recupera para a memória - do cinema brasileiro e latino-americano e do cinema de mulheres - os caminhos desta esquecida produtora e de seu único e inacabado filme de ficção, estudo realizado a partir de seu roteiro original do filme e de fontes jornalísticas. Graças a estas, o trabalho abre espaço para pensar a presença feminina no meio e sua recepção na imprensa. $\mathrm{Na}$ verdade, longe de ser silenciada, a cobertura jornalística feita sobre a produtora e o processo de preparação do filme é abundante, mas valorizando o 
que considera "pitoresco", adotando um tom "desconfiado" e de caráter misógino, atingindo tons inequivocamente lesbofóbicos, quando ambas as produtoras, posteriormente, se voltam para o teatro.

Encerram o dossiê dois artigos atravessados e tensionados pelos processos ditatoriais uruguaio e chileno. $O$ de Mariel Balás, "Diapomontajes: Audiovisuales de transición en el Uruguay de mediados de 1980", investiga este tipo de produção durante os anos 1980, no Uruguai, e seu caráter transicional entre fotoquímica e fita de vídeo. Esta tecnologia, que combina o uso de diapositivos e trilha sonora, teve seu momento de apogeu durante o período ditatorial (1973-1985), sendo utilizada por distintos coletivos de aficionados para projetos centrados em temas educativos, recreativos, turísticos ou históricos que circulavam, principalmente, em concursos organizados por entidades culturais, embora outras esferas de difusão e uso fossem a publicidade e a educação. Dessa prática tão pouco tratada na academia, Balás descreve os processos de construção e projeção, explicando seu caráter performativo, que varia de acordo com o público, as condições materiais do local e a disponibilidade de projetores. Seu artigo se concentra nas diapomontagens Destituidos (1984), do Centro de Medios Audiovisuales (CEMA), e La gesta de una conciencia (1985), da produtora Imágenes, e nos alcances políticos que tiveram nesse período de transição e de profunda crise econômica. $\mathrm{O}$ texto finaliza problematizando, como outros artigos do dossiê, a materialidade do próprio objeto de estudo: a preservação, o acesso e a reconstrução dos materiais audiovisuais. Finalmente, voltado às relações entre cinema e som, Martín Farías examina, em seu artigo, "Música y Sonido en el Cine Chileno: Nuevas voces para viejas historias", o cinema chileno a partir de dois documentários bem conhecidos: Mimbre (Sergio Bravo, 1957-1959) e La batalla de Chile (Patricio Guzmán, 1975-1979). Graças a acompanhamento exaustivo de fontes, o artigo trata das modificações no uso do som ao longo do tempo e seu impacto na historiografia. No caso de Mimbre, produzido em 1957, mas musicalizada por Violeta Parra apenas em 1959, e cuja locução, mencionada em fontes jornalísticas, se perdeu, o conhecimento desses fatos modifica significativamente sua recepção e exegese. Um caso similar ocorre com as múltiplas variações operadas por Guzmán em La batalla de Chile, no que diz respeito tanto ao roteiro quanto aos locutores (na primeira versão, de origem cubana, na segunda, espanhola e na terceira, feita pelo próprio realizador). São modificações que desencadeiam uma reflexão sobre as implicações 
simbólicas, ideológicas e políticas que as sucessivas atribuições geográficas à locução acarretam, como no caso anterior, na recepção do filme, e que continuam a justificar uma maior pesquisa e análise das trilhas sonoras destes e doutros filmes.

Se o objetivo do dossiê era, em sua origem, investigar o estado atual da pesquisa histórica sobre o cinema no mundo latino-americano, os seis artigos que apresentamos o cumprem plenamente: são excelentes exemplos das novas formas de uso do arquivo e seus documentos, de fazer história e de olhar, com o horizonte transformado e dotado de ação transformadora, para o objeto. Eles são, em suma, um instantâneo da investigação vital em curso no continente e das muitas questões em aberto deixadas para pesquisas futuras.

\section{Referências}

Caimari, Lila. 2017. La vida en el archivo. Goces, tedios y desvíos en el ofício de la historia. Buenos Aires: Siglo XXI.

Chauvin, Irene Depetris e Taccetta, Natalia, coord. 2019. Afectos, historia y cultura visual: una aproximación indisciplinada. Buenos Aires: Prometeo Libros.

Cossalter, Javier, coord. 2021. Filmografías comentadas en América Latina. Buenos Aires: Editorial de la Facultad de Filosofía y Letras Universidad de Buenos Aires.

Cuarterolo, Andrea. 2017. "El archivo en la época de su reproductibilidad técnica. Recursos digitales para el estudio del cine silente latino-americano." Vivomatografías. Revista de estudios sobre precine y cine silente en Latinoamérica 3: 416-447. http://www.vivomatografias.com/index.php/vmfs/article/view $\angle 143$. Acesso em 20 de dezembro de 2021.

Gionco, Pamela. 2020. "La digitalización de revistas de cine latinoamericanas: modelos para armar." Imagofagia. Revista de la Asociación Argentina de Estudios de Cine y Audiovisual 22: 332363.

http://www.asaeca.org/imagofagia/index.php/imagofagia/articl e/view/2108. Acesso em 27 de dezembro de 2021.

Le Goff, Jacques e Nora, Pierre, orgs. 1976a. História: novas abordagens. Rio de Janeiro: Francisco Alves Ed. 
Alves Ed.

1976b. História: novos objetos. Rio de Janeiro: Francisco 1976c. História: novos problemas. Rio de Janeiro: Francisco Alves Ed.

Lindeperg, Sylvie. 2007. Nuit et brouillard. Un film dans l'histoire. Paris: Odile Jacob.

Lusnich, Ana Laura, Aisemberg, Alicia e Cuarterolo, Andrea, eds. 2017. Pantallas transnacionales. El cine argentino y mexicano del período clásico. Buenos Aires: Imago Mundi.

Meneses, Ulpiano Bezerra de. 2003. "Fontes visuais, cultura visual, história visual: balanço provisório, propostas cautelares." Revista Brasileira História 23(45): 11-36. https://doi.org/10.1590/S0102-01882003000100002.

Miquel, Ángel e Wood, David M. J. 2016. "Introducción al dossier: El cine de compilación de la Revolución Mexicana." Vivomatografías. Revista de estudios sobre precine y cine silente en Latinoamérica 2: 6-12. http://www.vivomatografias.com/index.php/vmfs/article/view L87. Acesso em 19 de dezembro de 2021.

Miranda, Laura e Riva, Lucía Rodríguez, coords. 2019. Diálogos cinematográficos entre España y Argentina. Vol. 1. Música, estrellas y escenarios compartidos (1930-1960). s/d: Shangrila Ediciones.

Morettin, Eduardo. 2014. "Acervos cinematográficos e pesquisa histórica: questões de método.” Revista Esboços 21(31): 50-67. http://dx.doi.org/10.5007/2175-7976.2014v21n31p50.

. 2021. "Cinemateca Brasileira: o sequestro e a destruição de nossa memória audiovisual." Revista Eletrônica de Comunicação, Informação e Inovação em Saúde 15(3): 553560. https://doi.org/10.29397/reciis.v15i3.2449.

Navitski, Rielle. 2014. "Reconsidering the Archive. Digitization and Latin American Film Historiography." Cinema Journal 54 (1): 121-128.

Navitski, Rielle e Poppe, Nicolas, eds. 2017. Cosmopolitan Film Cultures in Latin America, 1896-1960. Bloomington: Indiana University Press. 
Paranaguá, Paulo Antonio. 2015. "Memoria e historia del cine en América Latina.” Em: Cine mudo latinoamericano: Inicios, nación, vanguardias y transición, editado por Aurelio de los Reyes e David Wood, pp. 21-32. México: UNAM.

Pinta, María Fernanda e Sala, Jorge, coord. 2020. “Dossier: Prácticas intermediales en la escena artística latinoamericana del siglo XXI: convergencias, hibridaciones y expansiones." Caiana. Revista de Historia del Arte y Cultura Visual del Centro Argentino de Investigadores de Arte (CAIA) 17: 83-87. http://caiana.caia.org.ar/template/caiana.php?pag=articles/articl e 2.php\&obj=376\&vol=17. Acesso em 19 de dezembro de 2021.

Poppe, Nicolás, coord. 2018. "Hacia nuevos horizontes de la investigación. La crítica videográfica y los estudios del precine y el cine silente." Vivomatografías. Revista de estudios sobre precine y cine silente en Latinoamérica 4: 116-128. http://www.vivomatografias.com/index.php/vmfs/article/view $\angle 179$. Acesso em 29 de dezembro de 2021.

Prelinger, Rick. 2007. "It's Only a Moving Image. Archives, Access and the Social Contract." Palestra proferida em Future Histories of the Moving Image, Sunderland University, Reino Unido, novembro de

2007. https://old.diglib.org/forums/fall2007/presentations/Prelinger. pdf. Acesso em 19 de dezembro de 2021.

Sánchez-Biosca, Vicente. 2017. "Imagens de atrocidade e modalidades do olhar questões de método." Em: Cinema $e$ história: circularidades, arquivos e experiência estética, organizado por Carolina Amaral de Aguiar, Danielle Crepaldi Carvalho, Eduardo Morettin, Lúcia Ramos Monteiro e Margarida Adamatti, pp. 396438. Porto Alegre: Sulina.

Schvarzman, Sheila. 2017. "Escrever a história do cinema brasileiro no século XXI: desconstruir a história no singular e escrever a história no plural.” Rumores 11(21): 132-150.

Tadeo Fuica, Beatriz e Barrow, Sarah, coord. 2015. "(In)visible Cinemas: Reusing Archival Footage en Latin American Cinema." New Cinemas: Journal of Contemporary Film 13(1): 3-8. https://doi.org/10.1386/ncin.13.1.3 7.

Torello, Georgina. 2020. "Introducción al dossier. El cine europeo en Latinoamérica: desembarco, tensiones y apropiaciones." 
Vivomatografías. Revista de estudios sobre precine y cine silente en Latinoamérica 6: 6-18. http://www.vivomatografias.com/index.php/vmfs/article/view ¿346. Acesso em 19 de dezembro de 2021.

Torello, Georgina e Lacruz, Cecilia. 2020. "Cine en América Latina: dinámicas de un intercambio histórico." Revista Encuentros Latinoamericanos (segunda época) 4(2): 1-7, https://ojs.fhce.edu.uy/index.php/enclat/article/view/876.

Acesso em 29 de dezembro de 2021.

Zavala Alvarado, Lauro. 2017. "Presentación sobre los estudios cinematográficos en la región latinoamericana (2000-2016).” Miguel Hernández Communication Journal 8, 13-18. https://revistas.innovacionumh.es/index.php/mhcj/article/dow nload/179/320/815. Acesso em 29 de dezembro de 2021.

\section{Historical Research in Latin-American Cinema: Perspectives and challenges in the digital age}

ABSTRACT The main purpose of this special issue is to reflect on the current state of cinema historical research in the Latin American world, considering the challenges it poses to contemporaneity and existing perspectives. One of the main tasks of film historians is to develop a system for understanding past experiences that link film analysis and production data - in their different manifestations - with contextual issues. We aim to assess the state of new approaches, new objects and new problems in recent historical research and explore the possibilities in articulating theory and practice. As widely known, Latin American audiovisual archives and cinémathèques have been at great risk, most recently, the Cinemateca Brasileira. It is never enough to emphasize the strategic importance of these collections, since they store films, posters, scripts and reports. Articulated by the researcher's chosen methods, the formation of thematic and conceptual axes or the constitution of a periodization, these documents enable us to build the history of a certain cinematography. In 2020, digital technologies were the privileged form of access to film and documentary sources, which has undoubtedly accentuated the challenges posed since the early 21st century. If our visual understanding of film is changing with its display on cell phones and computers, there is also a growing loss of contact with the materiality of the sources due to the continuous use of digital databases and repositories of documentary sources. To think about the implications of this situation in cinema history is one of the objectives of this special issue.

KEYW ORDS Film historiography; historical research; history of cinema.

aniki A Pesquisa Histórica no Cinema Latino-americano | Historical Research in Latin-american Cinema 


\section{Investigación Histórica en el Cine Latinoamericano: Perspectivas y desafíos en la era digital}

RESUMEN El principal objetivo del dossier es reflexionar sobre el estado actual de la investigación histórica sobre cine en el mundo latinoamericano, considerando los desafíos que impone para la contemporaneidad y las perspectivas existentes. Los esfuerzos por desarrollar un sistema de comprensión de las experiencias pasadas que vincule el análisis fílmico y los datos de la producción cinematográfica - en sus diferentes manifestaciones - con cuestiones contextuales son una de las tareas del historiador. Nuestra intención es evaluar el estado de los nuevos enfoques, nuevos objetos y nuevos problemas en las investigaciones históricas más recientes y los posibles caminos a seguir en la articulación entre teoría y práctica. Como se sabe, la investigación centrada en la historia del cine dependió siempre de los archivos audiovisuales y cinematecas, muchas de ellas en riesgo en América Latina, como en el caso de la Cinemateca Brasileira. Es necesario enfatizar siempre la importancia estratégica de las colecciones, ya que almacenan películas, afiches, guiones, informes - documentos que, articulados por el investigador al método elegido, a la formación de núcleos temáticos y conceptuales y a la constitución de una periodización, construyen la historia de una cinematografía. En 2020 la forma privilegiada de acceso a las fuentes fue digital, lo que sin duda acentuó los desafíos planteados desde principios del siglo XXI. Si la dimensión de aprehensión visual de las películas está cambiando con su visionado en teléfonos celulares y computadoras, también hay una pérdida creciente de contacto con la materialidad de las fuentes que surge del uso continuo de bases de datos y repositorios digitales. Pensar en las implicaciones de esta situación para la investigación histórica del cine es uno de los objetivos del presente dossier.

PALABRAS CLAVE Historiografía del cine; investigación histórica; historia del cine.

aniki A Pesquisa Histórica no Cinema Latino-americano | Historical Research in Latin-american Cinema 